Note

\section{Grain Boundary Pop-in, Yield Point Phenomenon and Carbon Segregation in Aged Low Carbon Steel}

\author{
Zhengyan SHEN, ${ }^{1)}$ Bilei WANG, ${ }^{1)}$ Gaofei LIANG, ${ }^{2)}$ \\ Yunhu ZHANG, ${ }^{1)} \mathrm{Ke} \mathrm{HAN}^{3)}$ and Changjiang $\mathrm{SONG}^{1) *}$
}

1) State Key Laboratory of Advanced Special Steel, Shanghai Key Laboratory of Advanced Ferrometallurgy, School of Materials Science and Engineering, Shanghai University, Shanghai, 200072 China.

2) Technology Center of Baoshan Iron \& Steel Co. Ltd, Shanghai, 201900 China.

3) National High Magnetic Field Laboratory, Florida State University, 1800 East Paul Dirac Drive, Tallahassee, FL 32310 USA.

(Received on July 21, 2017; accepted on October 3, 2017)

Nanoindentation measurements, tensile tests, and carbon concentration analyses were conducted to study yield behaviors in asreceived, aged, and prestrained low carbon steel. In aged sample, steel showed both yield point phenomenon (YPP) and grain boundary (GB) pop-ins besides initial pop-in, while steels in other two states showed no YPP and only the initial pop-in. 3-dimensional atom probe (3DAP) analysis in both as-received and aged samples showed that carbon content in the matrix decreased significantly after aging treatment, which is believed to contribute to the occurrence of both YPP and GB pop-in.

KEY WORDS: yield point phenomenon; nanoindentation; grain boundary pop-in; low carbon steel.

\section{Introduction}

Low carbon steels are popular panel materials for both vehicles and appliances. These steels frequently suffer stretcher-strain defects caused by yield point phenomenon (YPP). YPP, a yielding feature showed in stress-strain curves, is visible as Lüders bands in annealed low carbon steels. This phenomenon has been a concern for a long time. Hence, understanding the mechanism of YPP is of high academic and commercial importance.

Most researchers relate YPP in steels to interstitial atoms such as $\mathrm{C}$ or $\mathrm{N}$. Low et al. ${ }^{1)}$ reported that removal of both $\mathrm{C}$ and $\mathrm{N}$ in mild steels by wet hydrogen treatment can make the yield point disappear. It is well accepted that the interaction between interstitial atoms and dislocations form "Cottrell atmosphere", ${ }^{2)}$ and the unpinning of dislocations from atmospheres causes the yield point. Hahn ${ }^{3)}$ pointed out that YPP is a consequence of rapid dislocation multiplication after initial yield. Other researchers suggested that YPP is due to the fastening of dislocations by interstitial atoms at grain boundaries. ${ }^{4,5)}$ This inconsistence in explanations

\footnotetext{
* Corresponding author: E-mail: riversxiao@163.com DOI: http://dx.doi.org/10.2355/isijinternational.ISIJINT-2017-426
}

of YPP calls for further studies by new technology that characterizes materials in small regions with high spatial resolution.

Recently, nanoindentation has been used to investigate the mechanical properties of materials at micro-scales. In load-displacement curves of nanoindentation, both "initial pop-in"6,7) and "grain boundary (GB) pop-in" ${ }^{\text {"11) }}$ phenomena have been observed. In initial pop-in, a sudden increase in the displacement occurs during the early stage of mechanical contact, which is attributable to the nucleation or multiplication of dislocations. ${ }^{12,13)}$ Ahn et al ${ }^{14)}$ related the initial pop-in to YPP. But, this connection was ruled out because in steel without YPP initial pop-in was also observed. ${ }^{7} \mathrm{~GB}$ pop-in occurs at higher load than initial pop-in. The GB pop-in was related to interfacial yielding near the grain boundary. ${ }^{15)}$ The phenomenon was considered to be caused by the unpinning of dislocations from grain boundary. ${ }^{10)} \mathrm{GB}$ pop-in was observed in body-centered cubic metals (e.g. Iron and Niobium) which usually show YPP. ${ }^{8-11)}$ Thus, it is of interest to study YPP and GB pop-in together using the same samples. This paper reports our measurements of YPP by tensile tests, and both initial pop-in and GB pop-in by nanoindentation in a commercial low carbon steel and our understanding of YPP mechanisms.

\section{Experimental Methods}

As-received samples are commercial low carbon steel sheets without YPP, and the average grain size is about $8 \mu \mathrm{m}$. The chemical composition of the steel is Fe- $0.025 \mathrm{C}$ $0.0018 \mathrm{~N}-0.047 \mathrm{Al}-0.18 \mathrm{Mn}-0.015 \mathrm{Cr}(\mathrm{wt} \%)$. An as-received sample was aged at $220^{\circ} \mathrm{C}$ for $6 \mathrm{~h}$ to create YPP. The aged sample was then deformed under a tensile strain of $5 \%$ to remove YPP. Tensile tests were performed on as-received, aged and deformed samples at a strain rate of $1 \times 10^{-3} / \mathrm{s}$ at room temperature. The interstitial content of aged and asreceived samples was measured in a 3-dimensional atom probe (3DAP; LEAP 4000x HR).

The specimens prepared for nanoindentation tests were mechanically polished using 2500 -grit $\mathrm{SiC}$ paper and then electropolished for about $1 \mathrm{~min}$ in a solution composed of $6 \%$ perchloric acid, $14 \%$ water, and $80 \%$ ethanol at $278 \mathrm{~K}$ under a potential of $40 \mathrm{~V}$. Nanoindentation tests were performed using a Hysitron Triboindenter with a Berkovich diamond tip. The angle between Berkovich indenter and rolling direction of samples remained the same for all the tests. The maximum force was $10 \mathrm{mN}$ and loading rate was $2 \mathrm{mN} / \mathrm{s}$. Indentations in each sample were made in a $4 \times 10$ array with $20 \mu \mathrm{m}$ intervals between indents. A Scanning Electron Microscopy (SEM) was used to examine the indentations.

\section{Results and Discussions}

The stress-strain curves of samples in as-received, aged, and 5\% strained after aging are shown in Fig. 1. YPP occurs with upper and lower yield points in aged samples, but not in samples of as-received or $5 \%$ prestrained steels.

Figure 2 shows the representative load-depth curves of indentations in low carbon steels. Initial pop-in phenomena occur under loads less than $1.1 \mathrm{mN}$ in most tests in as- 


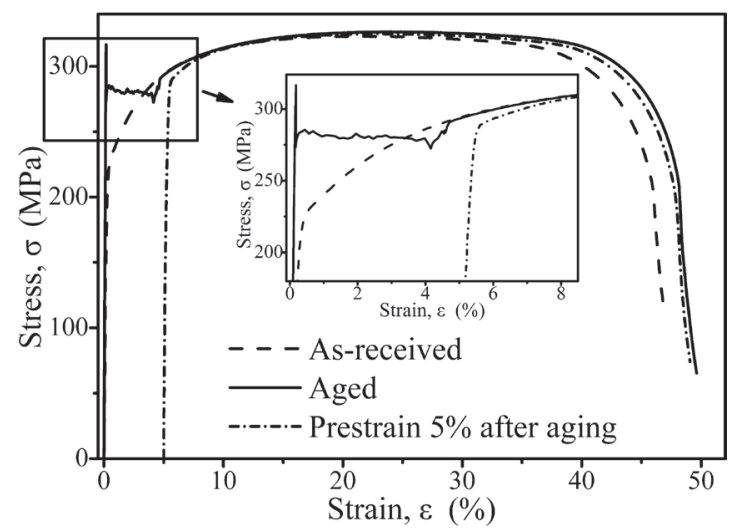

Fig. 1. Stress-strain curves for low carbon steels: as-received, aged, prestrained 5\% after aging. An inset shows the enlarged stress-strain curves in the YPP region.
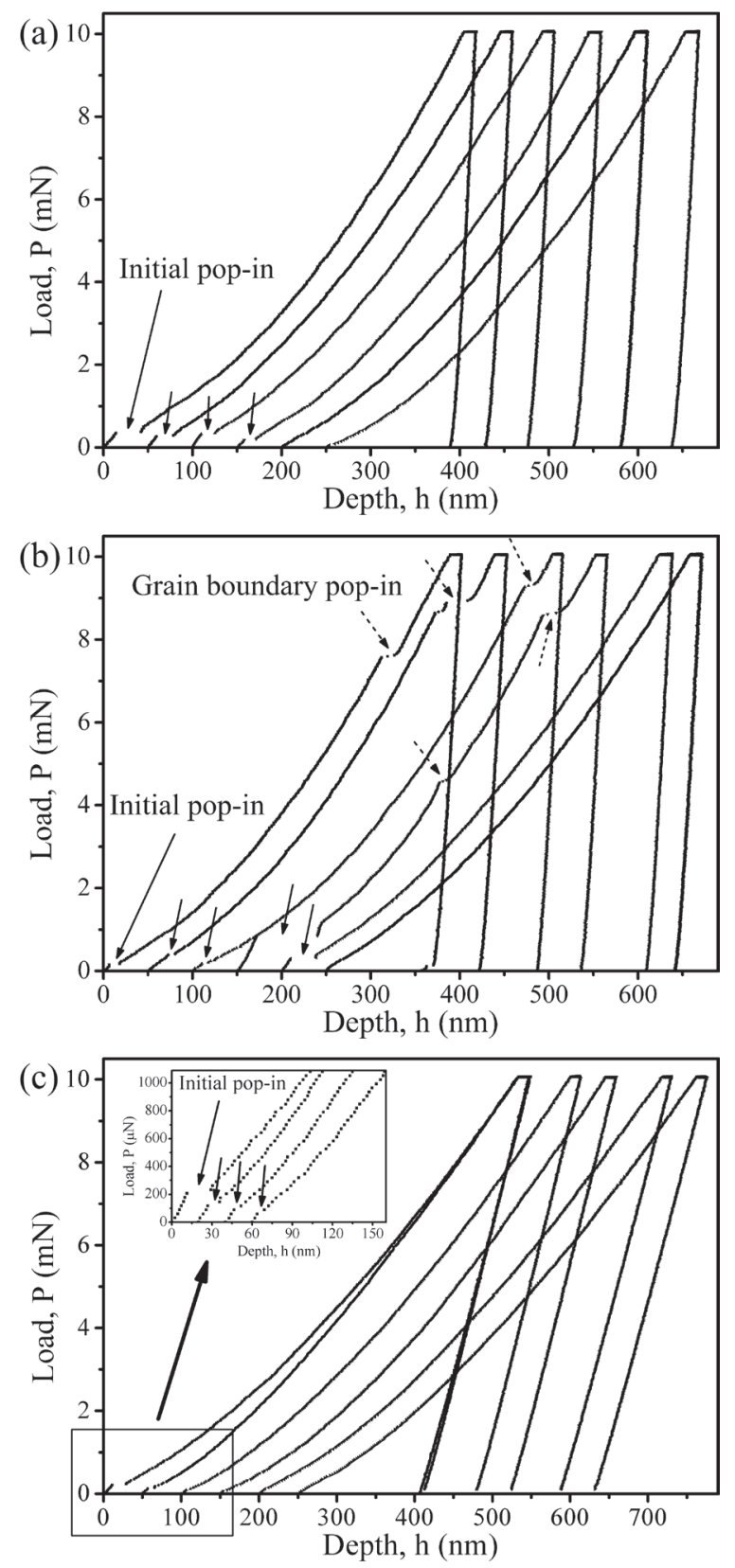

Fig. 2. Representative load-depth curves event in low carbon steels: (a) as-received sample (No one in 40 indentations shows GB pop-in), (b) aged sample (14 in 40 indentations show GB pop-in), (c) prestrain 5\% sample after aging (No one in 40 indentations shows GB pop-in). received (Fig. 2(a)), aged (Fig. 2(b)) and 5\%-strained (Fig. 2(c)) samples. 14 of our 40 tests of aged samples exhibited GB pop-in that was triggered at higher load than that for initial pop-in plateau. Moreover, GB pop-in in aged sample was found when indentation was made in the proximity of a boundary (Fig. 3(a)). Indents in the grain interior showed no GB pop-in (Fig. 3(b)).

In our experiments, not all the indentations close to the boundaries showed GB pop-in in a given aged sample. This is not unusual because, according to previous researchers, several factors affect the occurrence of GB pop-in: distance between the indentation and nearest $\mathrm{GB},{ }^{8)}$ dislocation density, ${ }^{10)}$ orientation between two adjacent grains, ${ }^{11)}$ and presence of impurities within grain boundaries. ${ }^{9,10)}$ No test (out of 40 measurements), however, showed GB pop-in in as-received and prestrained samples. Since GB pop-in appeared only in sample with YPP, GB pop-in and YPP may be related to similar microstructure changes resulted from aging.

The load-depth curve can be converted into $(\mathrm{P} / \mathrm{h}) \mathrm{vs} . \mathrm{h}$ curve, which was used to analyze the plastic deformation mechanisms for nanoindentation. ${ }^{16)}$ The slope of $(\mathrm{P} / \mathrm{h}) \mathrm{vs}$. h curve, $d(P / h) / d h$, can be used to describe work-hardening rate. ${ }^{11)}$ In our aged sample, GB pop-in caused a discontinuity in slope at high load region in $(\mathrm{P} / \mathrm{h})$ vs. h curve (Fig. 4(a)). The slope of $(\mathrm{P} / \mathrm{h})$ vs. h plot decreases after GB pop-in, which suggests that the stress required to activate dislocation source at or near the boundary was reduced after initial yield of the GB. ${ }^{11)}$ In addition, the slopes in asreceived sample are hardly changed after the initial pop-in, whose values are lower than those before GB pop-in in aged
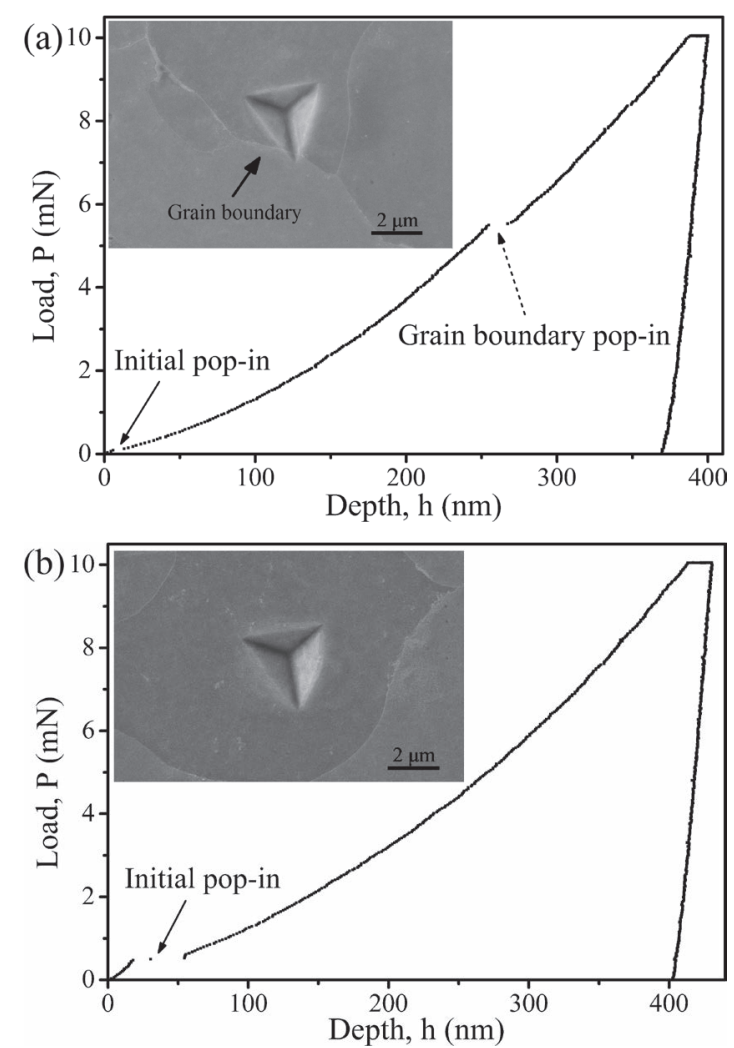

Fig. 3. Load-depth curves and its corresponding SEM images of indents in aged sample: (a) with GB pop-in where center of the indenter is about $1.4 \mu \mathrm{m}$ from GB, (b) without GB pop-in, where center of the indenter is about $4.1 \mu \mathrm{m}$ from GB. 

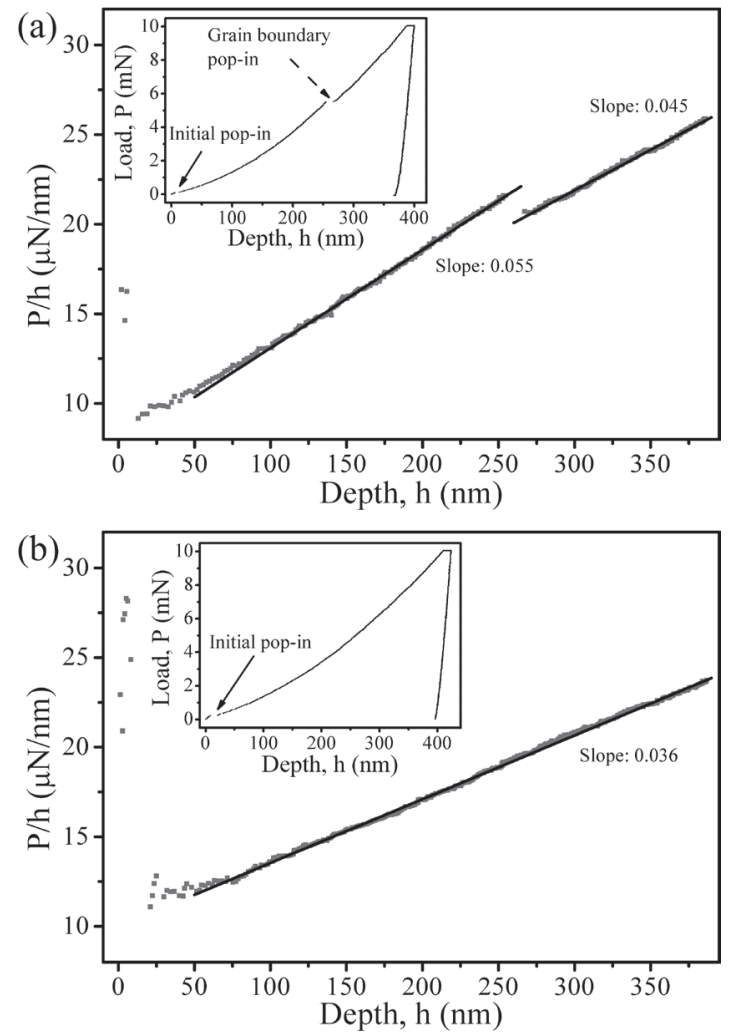

Fig. 4. Typical $(\mathrm{P} / \mathrm{h})$ vs. h plots for low carbon steels: (a) aged sample, (b) as-received sample.

sample (see an example in Fig. 4(b)). This suggests slip transfer in aged sample is harder than that in as-received sample, which can be considered as the effect of grain boundary hardening. ${ }^{17)}$ This can be verified by comparison of the difference in yield strength in two types of samples (Fig. 1). Previous researchers established a relationship between Lüders strain and work-hardening rate at lower yield stress (LYS): ${ }^{18)}$

$$
\varepsilon_{\mathrm{L}} \times(\mathrm{d} \sigma / \mathrm{d} \varepsilon)_{\mathrm{LYS}}=\Delta .
$$

where $\varepsilon_{\mathrm{L}}$ is Lüders strain (also called yield point elongation, YPP includes yield drops and Lüders strain), $(\mathrm{d} \sigma / \mathrm{d} \varepsilon)_{\mathrm{LYS}}$ is the working-hardening rate at LYS and $\Delta$ is constant. Equation (1) indicates that decreasing $(\mathrm{d} \sigma / \mathrm{d} \varepsilon)_{\mathrm{LYS}}$ can enhance $\varepsilon_{\mathrm{L}}$. In this paper, the development of Lüders strain may be related to the reduction of $\mathrm{d}(\mathrm{P} / \mathrm{h}) / \mathrm{dh}$ after GB pop-in provided that $\mathrm{d}(\mathrm{P} / \mathrm{h}) / \mathrm{dh}$ is corresponding to the $(\mathrm{d} \sigma / \mathrm{d} \varepsilon)_{\mathrm{LYS}}$.

The carbon content was examined by 3DAP. Table 1 presents the measured chemical compositions in both asreceived and aged samples. It can be seen that the amount of carbon atoms significantly decreased from $178 \mathrm{ppm}$ to $77 \mathrm{ppm}$ after aging treatment, while such significant difference in other elements was not detected. Because total carbon content should remain the same in all examined samples, the carbon atoms depleted from the solid solution should have segregated to the grain boundaries or formed Cottrell atmospheres in aged sample. Cottrell atmospheres, however, were not found in our 3DAP testing results probably because the dislocations were not in probed areas. Our experiments indicate that the carbon segregation in aged sample can be linked to both macroscopic yielding and microscopic pop-in, suggesting some relationship between YPP and GB pop-in. According to Cottrell theory, YPP is
Table 1. Chemical compositions of the low carbon steel from 3DAP (atomic fraction in ppm).

\begin{tabular}{|c|c|c|c|c|c|c|c|}
\hline & $\mathrm{C}$ & S & $\mathrm{Al}$ & $\mathrm{Mn}$ & $\mathrm{P}$ & $\mathrm{Cr}$ & $\mathrm{Cu}$ \\
\hline As-received & $178 \pm 3$ & $18 \pm 1$ & $779 \pm 7$ & $1734 \pm 11$ & $238 \pm 4$ & $268 \pm 4$ & $268 \pm 4$ \\
\hline Aged & $77 \pm 1$ & $19 \pm 1$ & $801 \pm 4$ & $1650 \pm 6$ & $216 \pm 2$ & $247 \pm 2$ & $243 \pm 2$ \\
\hline
\end{tabular}

attributed to pinning of dislocations by interstitial atoms. Briton et al., on the other hand, pointed out that GB pop-in is due to interstitials pinning dislocations on or near the boundary. ${ }^{10)}$ So the contributions of carbon segregation to YPP and GB pop-in need to be investigated further.

\section{Conclusions}

In low carbon steel samples, both GB pop-ins and YPP were observed only in aged sample, not in as-received and $5 \%$ prestrained samples. 3 -dimensional atom probe (3DAP) analysis showed that carbon content in the matrix of the aged sample decreased significantly after aging treatment of the as-received sample, indicating carbon segregation to defects. Such segregation creates a strengthened barrier for slip transfer from the grain subject to indentation to the adjacent one so that GB pop-in occurs and for dislocation motion in the materials so that YPP happens.

\section{Acknowledgment}

This work was financially supported by National Natural Science Foundation of China (No. 51574162). 3DAP and Nanoindentation measurements were made in the Instrumental Analysis \& Research Center at Shanghai University. Part of work was undertaken in the National High Magnetic Field Laboratory, which is supported by NSF DMR-1157490 and the state of Florida. The authors would like to express sincere thanks for their support.

\section{REFERENCES}

1) J. R. Low and M. Gensamer: Trans. AIME, 158 (1944), 207.

2) A. H. Cottrell and B. A. Bilby: Proc. Phys. Soc., 62 (1949), 49.

3) G. T. Hahn: Acta Metall., 10 (1962), 727.

4) J. P. Bailon and J. M. Dorlot: Acta Metall., 19 (1971), 71.

5) V. Massardier and J. Merlin: Metall. Mater. Trans. A, 40A (2009), 1100 .

6) K. Sekido, T. Ohmura, T. Hara and K. Tsuzaki: Mater. Trans., 53 (2012), 907.

7) K. Sekido, T. Ohmura, L. Zhang, T. Hara and K. Tsuzaki: Mater. Sci. Eng. A, 530 (2011), 396.

8) M. G. Wang and A. H. W. Ngan: J. Mater. Res., 19 (2004), 2478.

9) W. A. Soer, K. E. Aifantis and J. T. M. De Hosson: Acta Mater., 53 (2005), 4665.

10) T. B. Britton, D. Randman and A. J. Wilkinson: J. Mater. Res., 24 (2009), 607.

11) S. Tsurekawa, Y. Chihara, K. Tashima, S. Ii and P. Lejček: J. Mater. Sci., 49 (2014), 4698.

12) W. W. Gerberich, J. C. Nelson, E. T. Lilleodden, P. Anderson and J. T. Wyrobek: Acta Mater., 44 (1996), 3585.

13) D. F. Bahr, D. E. Kramer and W. W. Gerberich: Acta Mater., 46 (1998), 3605.

14) T. H. Ahn, C. S. Oh, K. Lee, E. P. George and H. N. Han: J. Mater. Res., 27 (2012), 39.

15) K. E. Aifantis and A. H. W. Ngan: Mater. Sci. Eng. A, 459 (2007), 251.

16) K. Sekido, T. Ohmura, T. Sawaguchi, M. Koyama, H. W. Park and K. Tsuzaki: Scr. Mater., 65 (2011), 942.

17) Y. Ono, Y. Funakawa, K. Okuda, K. Seto, N. Ebisawa, K. Inoue and Y. Nagai: ISIJ Int., 57 (2017), 1273.

18) N. Tsuchida, Y. Tomota, K. Nagai and K. Fukaura: Scr. Mater., 54 (2006), 57 